\title{
DIANTE DA LEI TEM UM GUARDA: ACESSO À JUSTIÇA PARA MULHERES EM SITUAÇÃO DE VIOLÊNCIA DOMÉSTICA
}

\author{
Fabiane Simioni $^{1}$
}

\begin{abstract}
Resumo: A proposta deste ensaio é discutir, sob a inspiração da alegoria kafkaniana do guarda diante da lei, aspectos teóricos e práticos do acesso à justiça, a partir de um quadro empírico delimitado: a negação do acesso à justiça para mulheres em situação de violência doméstica. No texto de Kafka, o sacerdote manco e Josef K. encarnam uma representação da própria alegoria do guarda diante da lei. A relação entre os personagens, sob o aspecto do acesso à justiça enquanto direito fundamental, nos convida a reflexão sobre a uma atuação diligente quanto aos modos de produção, prevenção e coibição da violência doméstica e familiar contra as mulheres, nos termos art. $5^{\circ}$, inciso XXXV, da Constituição Federal brasileira.
\end{abstract}

Palavras-chaves: Franz Kafka; acesso à justiça; mulheres; violência doméstica

\section{A alegoria ${ }^{2}$ de Kafka e o acesso à justiça}

A alegoria do guarda diante da lei está inserida no capítulo nono do livro ' $O$ Processo', de Franz Kafka. O personagem principal da narrativa, Josef K., recebe a tarefa de levar um cliente italiano para uma visita turística na cidade. Josef K. era membro da associação para a manutenção dos monumentos artísticos da cidade e o cliente italiano um amante das artes. Na hora marcada, se encontrariam na catedral da cidade, espaço que reunia uma coleção de obras de arte.

Extremamente contrariado com a atribuição, totalmente imerso no conflito pessoal de seu julgamento, Josef K. chega ao local, mas não encontra o italiano. Há tão somente uma senhora ajoelhada contemplando um quadro de Maria e um sacerdote manco.

É esse sacerdote manco, revelando-se mais um dos agentes do tribunal que julga Josef K., que narra ao acusado a alegoria do guarda diante da lei.

A história começa:

"Nos documentos introdutórios à lei está escrito acerca desse engano: diante da lei está parado um guarda. Um homem do campo chega até esse guarda e pede para

\footnotetext{
${ }^{1}$ Doutoranda em Direito (UFRGS/CAPES). Professora de Direito Civil e Direitos Humanos no CESUCA.

${ }^{2}$ Alegoria tem origem na palavra grega allegoria. Define-se como a representação de uma idéia por meio de uma imagem. Um relato que problematiza uma questão filosófica sob a forma de um simbolismo. A alegoria pode ser considerada um simbolismo concreto, embora seu procedimento guarde frequentemente algo de abstrato, servindo para atingir o que a razão não consegue alcançar. Os personagens de uma alegoria são percebidos mais como a personificação de uma idéia do que como pessoas (Japiassú \& Marcondes, 1996: 06).
} 
entrar na lei. Mas o porteiro diz que ele não pode permitir sua entrada naquele momento. O homem reflete e pergunta, em seguida, se ele poderá entrar mais tarde. "Até é possível", diz o guarda, "mas agora não".

O homem do campo permanece imóvel. Não empreende qualquer esboço de resistência àquela negativa: não contra-argumenta, tampouco desiste. Permanece lá, em frente da lei, por anos a fio, à espera de uma oportunidade para entrar. Pouco antes de morrer, o homem pergunta ao guarda:

\begin{abstract}
"Se todos aspiram à lei", diz o homem, "como pode que em todos esses anos ninguém a não ser eu pediu para entrar?”. O guarda reconhece que o homem já está no fim, e no intuito de ainda alcançar seus ouvidos moribundos, grita com ele: "Aqui não poderia ser permitida a entrada de mais ninguém, pois essa entrada foi destinada apenas a ti. Agora eu vou embora e tranco-a".
\end{abstract}

A alegoria do guarda diante da lei como representação dos problemas do cidadão e da cidadã de camadas populares no acesso à justiça tem sido utilizada pela organização nãogovernamental THEMIS - Assessoria Jurídica e Estudos de Gênero, desde $1999^{3}$.

Esta ONG feminista, através do programa de formação de Promotoras Legais Populares (PLPs), se constitui em uma referência nacional e internacional para a formulação de uma política pública não estatal de acesso à justiça pelas mulheres oriundas de camadas populares. Segundo Feix (2004: 221), em Porto Alegre, foram capacitadas cerca de 250 mulheres, e no estado do Rio Grande do Sul, através de parceria com outras 11 entidades, foi implantada a Rede Estadual de Justiça e Gênero que capacitou mais de 800 PLPs, desde 2002. Em outras duas oportunidades de multiplicações nacionais da metodologia de capacitação legal, em 1999 e 2003, a ONG THEMIS treinou 30 entidades de todas as regiões do país, que, por sua vez já realizaram formações com aproximadamente 1.000 pessoas.

A principal demanda do trabalho desenvolvido pela ONG THEMIS e pelas PLPs é a ampliação das condições de acesso à justiça para mulheres em situação de violência doméstica.

\footnotetext{
${ }^{3}$ A THEMIS - Assessoria Jurídica e Estudos de Gênero é uma organização não governamental, formalmente criada em 1993, com sede em Porto Alegre/RS, Brasil. Atua na promoção e defesa dos direitos humanos das mulheres, em cooperação com instituições nacionais e internacionais, governos e entidades privadas. O nome THEMIS, homenagem à deusa grega da Justiça, indica a vocação do grupo para refletir e propor novas práticas referentes a gênero e direito, especialmente no questionamento dos fundamentos teóricos e culturais que determinam a distância entre a expectativa de justiça e sua realização para a grande maioria das mulheres em nossa sociedade. Para detalhamento da trajetória da ONG THEMIS na missão de acesso à justiça ver: FEIX. V. Sobre gênero e justiça: o Projeto Promotoras Legais Populares. Disponível em http://www.pagu.unicamp.br/sites/www.pagu.unicamp.br/files/colenc.01.a10.pdf. Acesso em 18/8/2012.
} 
Sabe-se que no Brasil o primeiro passo para a garantia do acesso à justiça para mulheres em situação de violência foi dado em 1980, em São Paulo, com o SOS Mulher, o primeiro serviço de atendimento direto (assistência social, jurídica e psicológica) para mulheres em situação de violência (Massula, 2005: 140) ${ }^{4}$.

A violência baseada nas desigualdades de gênero ${ }^{5}$ no âmbito doméstico está, desde a década de 70, no Brasil, na agenda dos debates políticos (Silveira [et. all.], 2008: 17).

As relações interpessoais marcadas pela violência fazem parte das formas de socialidade presentes nas sociedades complexas, onde as hierarquias e as desigualdades contribuem para a formação do arcabouço cultural de práticas discriminatórias e violentas em diferentes esferas sociais, das relações indivíduo-Estado até a vida cotidiana. Nesse sentido, essas situações de conflitualidade encontram legitimidade entre aqueles (sejam homens ou mulheres) que operam e agem segundo uma lógica androcêntrica baseada na dominação e subordinação imposta a todo aquele que não se encontra em igual ou superior posição hierárquica (Simioni \& Cruz, 2011).

As diferenças (de classe, de gênero, de geração, de raça/etnia, de orientação sexual) entre os sujeitos são apropriadas de um modo que o outro, o diferente da norma tornada hegemônica (diferente do modelo masculino tomado como o neutro) deve ser invisibilizado ou inferiorizado, tornando-se, desse modo, alvo preferencial de diferentes tipos de violências (Simioni \& Cruz, 2011).

No caso da violência contra as mulheres existem ingredientes que tornam essas conflitualidades ainda mais críticas. Nos espaços familiares, onde as relações interpessoais entre os sujeitos foram historicamente interpretadas como restritas e privadas, a complacência e a impunidade para com a violência praticada nesse âmbito encontraram sua legitimação social. Criou-se um senso comum apoiado na idéia de que o espaço doméstico é 'sagrado', acreditando-se que aquilo que ocorre entre familiares não ameaça a ordem social, ou que a

\footnotetext{
${ }^{4} \mathrm{O}$ processo de institucionalização das demandas dos movimentos feministas e de mulheres para combater a violência contra as mulheres pode ser sintetizado em três momentos: inicialmente, a criação das delegacias da mulher, em meados dos anos 1980; em segundo lugar, a implantação dos Juizados Especiais Criminais, em meados dos anos 1990; por último, a sanção da Lei 11.340, de 7 de agosto de 2006, popularmente conhecida como Lei "Maria da Penha" (Tavares [et. all.]: 2011: 03).

${ }^{5}$ Os estudos de gênero problematizam os diferentes valores culturais que são dados às mulheres e aos homens. Estes valores definem os comportamentos e as expectativas sobre como deve ser a mulher e como deve ser o homem na nossa sociedade. A principal referência para os estudos sobre gênero no Brasil veio do trabalho da historiadora e feminista americana Joan Scott, especialmente em artigo publicado em 1990: "Gênero: uma categoria útil para a análise histórica”, onde a autora formula sua definição de gênero. A categoria analítica de gênero, portanto, não se refere apenas às idéias, mas também às instituições, às estruturas, às práticas cotidianas, aos rituais e a tudo que constitui as relações sociais. Portanto, o gênero é a organização social da diferença entre os sexos. Ele não reflete a realidade biológica primeira, mas constrói o sentido dessa realidade.
} 
forma como aqueles sujeitos se relacionam é natural, operando-se com a ficção de que a liberdade é vivida na esfera pública e a privação na esfera privada (Simioni \& Cruz, 2011).

Todavia, a conflitualidade no âmbito doméstico deve ser compreendida como um fenômeno relacional, fazendo parte daquela cena os diversos sujeitos e atores sociais, para além de uma polarização reificada entre agressor e vítima. Daí a importância da análise dos contextos e significados atribuídos por estes sujeitos. Nessa perspectiva, não se pode definir a violência como uma categoria a priori, mas configurada segundo as regras do espaço social no qual se manifesta (Sarti [et. all.], 2006:169).

A proposta deste ensaio é discutir, sob a inspiração da metáfora kafkaniana do guarda diante da lei, aspectos teóricos e práticos do acesso à justiça, a partir de um quadro empírico delimitado: a negação do acesso à justiça para mulheres em situação de violência doméstica.

No texto de Kafka, o sacerdote e Josef K. encarnam uma representação da própria metáfora do guarda diante da lei. O personagem Josef K. quer justiça pra si, pois está sendo acusado de algo que não lhe é dado conhecer, por um tribunal que não the oportuniza qualquer defesa. De outra parte, não é sem razão que o tribunal esteja sendo representado por um homem, na posição de sacerdote e manco. Se para uns a justiça é uma figura cega, na alegoria kafkaniana a justiça é representada por uma figura masculina, claudicante, que domina os ofícios e mistérios de uma crença em uma 'verdade irrefutável de origem sobrenatural ${ }^{\prime 6}$.

A relação entre os personagens, sob o aspecto do acesso à justiça enquanto um direito fundamental, nos convida a reflexão sobre a uma atuação diligente quanto aos modos de produção, prevenção e coibição da violência doméstica e familiar contra as mulheres, nos termos art. $5^{\circ}$, inciso XXXV, da Constituição Federal brasileira.

\section{Os fundamentos do direito de acesso à justiça}

Segundo o art. 5, inciso XXXV, da Constituição Federal de 1988, “a lei não

excluirá da apreciação do Poder Judiciário lesão ou ameaça a direito". Trata-se, portanto,

\footnotetext{
${ }^{6}$ A crença em uma 'verdade irrefutável' é própria da atitude religiosa do verdadeiro crente: aquele que se liga a um Deus por ato voluntário, a partir de uma testemunha de origem sobrenatural. As relações da fé coma a razão estão no centro das doutrinas filosóficas clássicas e medievais. Para Tomás de Aquino, 'foi necessário, para a salvação do homem, que houvesse, fora das ciências filosóficas que a razão perscruta, uma doutrina diferente, procedendo de uma revelação divina' (Japiassú \& Marcondes, 1996: 100).
} 
de garantia constitucional que tem por objetivo assegurar aos sujeitos, seja individual ou coletivo, a efetiva prestação da função jurisdicional do Estado, melhor dizendo, o acesso à justiça.

O conteúdo do acesso à justiça, também denominado na doutrina como princípio da inafastabilidade do controle jurisdicional, se expressa pela garantia de que todos têm acesso à justiça para postular tutela jurisdicional preventiva ou reparatória relativamente a um direito. É o que Portanova (1999: 82) propõe quando afirma que o art. $5^{\circ}, \mathrm{XXXV}$, da CF verdadeiramente está abrindo o Poder Judiciário a todo tipo de discussão.

Isto implica considerar a existência de meios jurídico-legais que protejam as pessoas contra atos de particulares e atos do próprio poder público, quer os de administração, quer os legislativos ou jurisdicionais. Baracho (1995: 13) afirma que tal garantia constitucional leva à necessidade da existência de uma jurisdição em que o poder estatal seja exercido exclusiva e excludentemente por tribunais independentes prévia e legalmente estabelecidos, funcionalmente desenvolvidos de modo imparcial no processo e dirigidos à satisfação de interesses relevantes.

Nesse sentido, o processo judicial teria como principal fundamento ontológico assegurar a efetividade dos direitos e garantias fundamentais do cidadão e da cidadã, com base nas linhas principiológicas traçadas pela Constituição (Delgado, 1994: 38).

Segundo Nery Junior (2000: 94), o conteúdo da norma constitucional, em uma primeira vista, parece estar dirigida tão somente ao legislador. O comando, no entanto, atinge a todos indistintamente, pois as normas jurídicas não têm um destinatário certo e único. Em outras palavras, não pode o legislador e ninguém mais impedir que a pessoa vá a juízo deduzir pretensão e reivindicar direitos.

Cabe ressaltar que a "experiência" da ação, como referiu Grinover (1973: 73), deve ser estudada à luz do direito constitucional, como resultado do equilíbrio das forças políticas existentes na sociedade.

Todavia, não basta afirmar que o direito de ação, como direito público subjetivo, está em determinado ordenamento, constitucionalmente tutelado, nem que a situação subjetiva garantida pela Constituição representa o direito de ação e de defesa, a todos reconhecido.

A obrigação de resposta do Estado, diante do pedido de tutela do autor, é necessariamente genérica e abstrata; uma vez que administrar a justiça pode não significar a tutela dos direitos afirmados (Grinover, 1973; 76). Em outras palavras, a garantia 
constitucional do direito de ação não induz à prolação de sentença favorável ao autor, tampouco sentença de mérito, se ausentes as condições de ação.

O objeto do direito subjetivo de ação é a obtenção de tutela jurisdicional do Estado, portanto, entende-se por satisfeito e concretizado o objeto quando pronunciada a sentença, favorável ou não.

É necessário verificar, além da existência da tutela, a própria estrutura dessa tutela, ou seja, se a Constituição se limita a assegurar o direito à prestação jurisdicional, ou se também garante ao indivíduo uma tutela qualificada.

Nas fases sucessivas à propositura da ação é que o autor, assim como o réu, poderão encontrar obstáculos à obtenção de um provimento de mérito, por impedimentos supervenientes, internos ou mesmo estranhos ao processo. E a possibilidade de deduzir em juízo um direito, mediante a instauração do processo, ficaria reduzida a bem pouco, se não se garantissem constitucionalmente os meios para obter o pronunciamento do juiz sobra a razão do pedido.

Decorrem, assim, da tutela constitucional do direito de ação outras garantias, implícitas no preceito, operando-se no curso processual, com a finalidade de tutelar a efetividade da garantia constitucional. Os direitos de ação e de defesa seriam, neste caso, regulados pelo legislador de acordo com a estrutura e as exigências dos diversos procedimentos colocados à disposição pelo ordenamento jurídico.

Todavia, os marcos normativos do acesso à justiça não podem ser considerados exclusivamente sob a perspectiva processual. Embora o acesso à justiça seja reconhecidamente o ponto central da moderna processualística (Cappelletti \& Garth, 1988: 13-23), a dificuldade que muitas pessoas tem de utilizar plenamente a justiça e suas instituições vai além do direito formal do indivíduo agravado de propor ou contestar uma ação. Acessibilidade da justiça também significa a superação das barreiras que precisam ser pessoalmente superadas, antes que um direito possa ser efetivamente reivindicado através dos mecanismos jurídico-processuais.

Conforme advertência de Cappelletti \& Garth (1988: 9), o Estado não pode permanecer passivo com relação a ausência de aptidão de uma pessoa para reconhecer seus direitos e defendê-los adequadamente, na prática. A justiça, assim como outros bens, não pode ser exclusividade daqueles que podem enfrentar seus custos.

Com efeito, o direito ao acesso efetivo à justiça é de capital importância, uma vez que não basta declarar a titularidade de direitos fundamentais sem que se atribua mecanismos 
para sua efetiva reivindicação. $\mathrm{O}$ acesso à justiça deve ser considerado como requisito fundamental - o mais básico dos direitos humanos - de um sistema jurídico igualitário que pretenda garantir, e não apenas proclamar os direitos de todos, para Cappelletti \& Garth (1988: 11-12).

Embora não se possa negligenciar o acesso à representação judicial, o direito ao acesso à justiça deve ir mais além. Nos apoiamos na lição de Cappeletti \& Garth (1988: 08):

\footnotetext{
'A expressão 'acesso à justiça' é reconhecidamente de difícil definição, mas serve para determinar duas finalidades básicas do sistema jurídico - o sistema pelo qual as pessoas podem reivindicar seus direitos e/ou resolver seus litígios sob os auspícios do Estado. Primeiro, o sistema deve ser igualmente acessível a todos; segundo, ele deve produzir resultados que sejam individual e socialmente justos'. (Grifos nossos)
}

Nesse sentido, em um contexto de violência doméstica, é preciso que os agentes e as instituições compreendam as dinâmicas de conflitualidade que legitimam práticas de violação de direitos entre as partes, a fim tornarem-se concretamente acessíveis a todos e todas e de produzirem resultados socialmente justos.

\section{O guarda e a lei para as mulheres em situação de violência}

Os estudos que assumem uma perspectiva de gênero demonstram a inconteste situação de desigualdade na distribuição da justiça e o próprio acesso à justiça para as mulheres em situação de violência.

Uma das causas apontadas para a crise de legitimidade que afeta as instituições de justiça residiria no caráter seletivo de suas decisões, na forma desigual de distribuição da justiça e na aparente incapacidade deste sistema realizar sua promessa de igualdade de todos perante as leis.

Os estudos a respeito das práticas de justiça nos casos de violência contra a mulher têm demonstrado que a desigualdade no tratamento dos sujeitos envolvidos decorre do fato de os julgamentos terem por fundamento critérios extralegais ou exclusivamente morais, como por exemplo, o comportamento social e sexual dos homens e das mulheres envolvidos reputados desviantes da norma social hegemônica (Corrêa, 1983; Pimentel et all, 1998; Caulfield, 2000).

Conforme Pasinato (2004: 6-7), o peso desses critérios extralegais se evidenciaria no fato de que seus operadores (advogados/as, defensores/as públicos, promotores/as e juízes/as) 
tendem a trabalhar sob a perspectiva da preservação de instituições sociais como a família e o casamento, colocando em segundo plano a violação ao direito fundamental das mulheres de viverem uma vida sem ameaças a integridade física e psíquica.

Ora, se o Estado moderno é justamente a comunidade política que expropria dos particulares o direito de recorrer à violência como forma de resolução de seus conflitos, então, não há o direito de qualquer indivíduo ou grupo de fazer uso da violência como forma de resolução de conflitos interpessoais. Aqueles que estão autorizados ao uso da violência o fazem em circunstâncias determinadas, em obediência ao império da lei, isto é, aos constrangimentos impostos pelo ordenamento jurídico.

A prática sistemática de violência contra as mulheres mereceu reconhecimento internacional, a partir das conferências da ONU de Viena (1993), de Cairo (1994) e de Beijing (1995). A partir destes marcos jurídicos internacionais foi expressamente declarado que os direitos das mulheres são direitos humanos. Essa abordagem permitiu que a denúncia das situações de violência contra as mulheres pudesse se constituir como um problema público e político, retirando-o da esfera do privado, da sacralidade da unidade doméstica e familiar. Permite também cobrar dos Estados o cumprimento de compromissos que assumiram ao assinar e ratificar as convenções internacionais de proteção dos direitos das mulheres, para erradicar, punir e prevenir todas as formas de violência e discriminação contra as mulheres.

Nesse sentido, diante de uma situação de violência contra a mulher, cabe ao Estado, através dos poderes constituídos, intervir de modo a reparar e cessar as violações de direitos ocorridas.

Aqui nesse espaço, nos ocupamos especificamente dos deveres dos agentes jurídicolegais - não exclusivamente - de garantir o acesso à justiça àquelas que se encontram em uma condição de cidadania de segunda classe.

É necessário explicitar que a condição de cidadania de segunda classe não é exclusividade das mulheres. Em uma sociedade hierárquica e desigual como a brasileira, o que se torna representado no campo político, é apenas uma parte dos interesses presentes no mundo vivido. Há um inequívoco descompasso entre a norma igualitária e a desigualdade social, os modos de vida popular e a representação pública destes, um descompasso entre a pretensão normativa de pluralismo e a seletividade limitadora no acesso à legitimidade social. Tal condição se reflete não somente em relação às mulheres, mas também em relação aos indivíduos que não correspondem à categoria a priori de sujeito universal de direitos: homem, branco, heterossexual e consumidor. 
Significa dizer, em última análise, que o império da autonomia e das escolhas morais individuais ou o pragmatismo da igualdade formal utilizado pelas instituições merecem sempre o enfrentamento das externalidades ditadas pela desigualdade de poder entre sujeitos concretos atravessados pelos diferentes marcadores sociais: classe social, raça/etnia, gênero, geração e orientação sexual. São essas externalidades que, embora não explicitamente referidas no simbolismo do guarda kafkaniano, estão presentes na interpretação contemporânea que empreendemos do acesso à justiça.

De acordo com o relatório 'O Progresso das Mulheres no Mundo: em busca da justiça (2011-2012)', do órgão das Nações Unidas para a Igualdade de Gênero e o Empoderamento das Mulheres (ONU Mulheres), a justiça segue inacessível para milhões de mulheres no mundo. Para garantir que a justiça se torne uma realidade para todas as mulheres, o relatório recomenda aos governos:

(i) Revogação das leis que discriminam as mulheres e garantia de uma legislação para protegê-las contra a violência e a desigualdade praticada no lar e no trabalho.

(ii) Apoio aos serviços inovadores de justiça, incluindo centros de atendimento integral, assistência jurídica e judicial para assegurar o acesso das mulheres à justiça.

(iii) Emprego de mais mulheres em cargos de administração da justiça. Como policiais, juízas, legisladoras e ativistas, para que as mulheres de todas as regiões façam a diferença e provoquem mudanças.

(iv) Investimento em sistemas de justiça que possam responder às necessidades das mulheres. Os países doadores distribuem anualmente 4,2 bilhões de dólares em ajuda para reformas judiciais, mas apenas $5 \%$ desse total é destinado às demandas das mulheres e das meninas.

O relatório aponta ainda que a violência doméstica atualmente é proibida em 125 países, embora 603 milhões de mulheres ainda vivem em países onde esta forma de violência não é considerada crime. Pelo menos 52 países haviam criminalizado a violação conjugal, até o ano de 2011. No entanto, mais de 2,6 milhões de mulheres vivem em países onde essa forma de violência não foi explicitamente definida como crime.

Em síntese, o relatório conclui que muitas vezes as leis não são cumpridas corretamente. Muitas mulheres têm medo de denunciar os crimes devido ao estigma social e à fragilidade dos sistemas judiciais. Os custos dos processos judiciais e as dificuldades, como a distância física dos fóruns e tribunais, podem representar desafios para as mulheres quando 
buscam a justiça. Os resultados destas questões estão evidenciados nas altas taxas de desistência em processos relacionados à violência de gênero.

Na América latina, conforme a análise de Massula (2005: 141), alguns pontos devem ser considerados chaves no processo de obstaculização do acesso à justiça:

(i) Desconhecimento: existe um desconhecimento real por parte da população acerca dos seus direitos. Muito embora o ordenamento jurídico brasileiro impeça a alegação de desconhecimento de obrigação decorrente da lei, para eximir-se do seu cumprimento, esse desconhecimento existe e acaba por obstaculizar o acesso à justiça, uma vez que não é possível pleitear algo que se desconhece.

(ii) Descrença: o complicado aparato judicial, seus prazos e formalidades aliados ao número cada vez maior de processos - incompatível com os recursos disponíveis para solução - e a demora cada vez maior para a obtenção de uma determinação judicial, produzem a sensação de que a justiça não é eficiente e que a prestação jurisdicional não é adequada às expectativas dos sujeitos.

(iii) Direito ou serviço? O número insuficiente de defensores públicos à disposição daqueles que não podem arcar com honorários aliado à desproporção entre a demanda e a oferta de juízes e servidores são problemas estruturais que fazem parte da atualidade do sistema jurídico-legal. Somam-se a esses o problema o transporte público deficitário e a insuficiência de programas sociais voltados para a erradicação da pobreza, entre outros fatores. Desta forma, uma vez que o Estado não consegue garantir o direito ao pleno acesso à justiça a quem não pode pagar por ela, restringe-se cada dia mais a justiça para aqueles que dispõem de insumos para pagar, voltando-se apenas aos sujeitos qualificados como consumidores.

(iv) Distanciamento: Em um país com as dimensões do Brasil é evidente a dificuldade em abranger a totalidade do território e da população garantindo-se seu acesso físico à justiça. Por outro lado, há que se considerar também o distanciamento institucional do Judiciário. A arquitetura dos fóruns e tribunais, a linguagem e vestimentas adotadas, promovem este distanciamento, mantendo os agentes jurídicos cada vez mais afastados dos "usuários" do Judiciário.

(v) Pobreza - trata-se de um fator que permeia todos os demais. Qualquer obstáculo ao acesso à justiça é majorado pela pobreza.

A pobreza, por sua vez, também atinge de maneira desigual homens e mulheres no Brasil. De acordo com a Pesquisa Mensal de Emprego, do Instituto Brasileiro de Geografia e Estatística (IBGE, 2012), as mulheres recebem, em média, 72,3\% do salário masculino, 
proporção que se mantém inalterada desde 2009. A presença das mulheres também é majoritária na população desocupada (57,9\% contra $42,1 \%$ de homens) e na população não economicamente ativa (63,9\% contra 36,1\% dos homens) em 2011. Em média, elas totalizavam 11,0 milhões de pessoas na força de trabalho, sendo 10,2 milhões ocupadas e 825 mil desocupadas. Na inatividade, o contingente feminino era de 11,5 milhões.

A Pesquisa Nacional de Amostra Domiciliar (PNAD/2009), realizada pelo IBGE, mostra que as mulheres tem escolaridade média de 7,4 anos de estudo contra 7 anos dos homens. Em média, as mulheres trabalhadoras do país tinham 8,7 anos de estudo, enquanto os homens apresentavam, aproximadamente, um ano a menos. Entretanto, o ramo de atividade que mais absorve as mulheres é o do trabalho doméstico (17,0\%), seguido do setor de comércio $(16,8 \%)$ e de educação, saúde e serviços sociais $(16,7 \%)$.

Outro dado que se destaca, nesse cenário, é a proporção majoritária de mulheres inseridas no trabalho doméstico. A categoria é composta por 7,2 milhões de pessoas, no entanto, é um nicho ocupacional feminino por excelência, no qual 93,0\% dos trabalhadores são mulheres, segundo o Instituto de Pesquisa Econômica Aplicada (IPEA, 2011). Por não produzir valor agregado e por realizar-se no âmbito doméstico, sempre foi uma ocupação marcada pela invisibilidade e subvalorização, pela precariedade e informalidade.

A Síntese de Indicadores Sociais, de 2010, do IBGE, revela que 55,0\% das trabalhadoras domésticas tinham de 25 a 44 anos e a proporção de pardas era de 49,6\%, mostrando uma interseção de desvantagens para as mulheres pardas. A maioria de trabalhadoras domésticas $(72,8 \%)$ não possuía carteira de trabalho assinada, o que evidencia a precariedade das condições de trabalho da maioria dessas mulheres. A escolaridade média encontrada foi de 6,1 anos de estudo e o rendimento médio foi da ordem de R\$ 395,20.

Conforme diagnóstico do Departamento Intersindical de Estatística e Estudos (DIEESE, 2011), entre 2006 e 2009, as trabalhadoras negras foram as que obtiveram o menor rendimento salarial do país, recebendo cerca de metade do salário pago às mulheres brancas. Em 2009, a média salarial das trabalhadoras negras foi de $\mathrm{R} \$ 558,00$ contra $\mathrm{R} \$ 1.001,00$ das mulheres brancas. O rendimento das mulheres brancas era, em 2009, 68\% do rendimento dos homens brancos e das mulheres negras apenas 40,33\%.

As estatísticas sucintamente apresentadas demonstram que, embora existam maiores oportunidades para as mulheres no mercado de trabalho brasileiro urbano, sua ascensão 
profissional ainda fica prejudicada, na comparação com os homens. Entre responsabilidades domésticas - de criação de filhos, sobrinhos e netos e reprodução das condições de trabalho de outros membros do núcleo familiar através da manutenção doméstica -, e as responsabilidades profissionais, a participação de muitas mulheres no mercado de trabalho é esporádica e fragmentada, frequentemente se resumindo numa série de subempregos temporários.

Como se pode observar há uma conjugação de fatores de infra e superestruturas que dificultam o acesso à justiça para homens e mulheres de camadas populares. A situação socioeconômica dos sujeitos certamente é condição básica para o sentimento de reconhecer-se como pertencente a uma comunidade política. Ao mesmo tempo em que a própria constituição do Poder Judiciário, sua estrutura, hierarquia e modus operandi também trabalham para dar contornos mais precisos ao poder e as funções do guarda diante da lei.

Concordamos com Bonetti [et. all.] (2002: 243) quando afirmam que a estrutura do Poder Judiciário precisa ser repensada e os/as operadores do Direito devem ser sensibilizados para uma releitura crítica do Direito capaz de enfrentar os mitos da neutralidade e da igualdade de todos e todas perante a lei. Esses mitos, afirmam as autoras, afastam e negam as características históricas e culturais presentes nas práticas dos sistemas de justiça, quando não reconhecem os preconceitos e as discriminações vigentes na sociedade brasileira. $\mathrm{O}$ resultado dessas práticas discriminatórias e preconceituosas é uma prestação jurisdicional inócua, distante do ideal de Justiça, incapaz de perceber os sujeitos de direitos em suas várias dimensões: gênero, raça/etnia, classe social e orientação sexual.

O exemplo que privilegiamos para análise da ineficácia da prestação jurisdicional é o caso do não reconhecimento do fenômeno social da violência doméstica e familiar contra a mulher como uma grave violação de direitos, por parte dos/das agentes que tem o dever legal de coibi-la.

No Brasil, a partir da sanção da Lei 11.340/2006, conhecida como Lei Maria da Penha $^{7}$, são criados mecanismos jurídico-legais para amparar as mulheres em situação de violência doméstica.

\footnotetext{
7 Em 1983, a cearense Maria da Penha sofreu duas tentativas de homicídio cometidas por seu então companheiro, em seu próprio domicílio. Os tiros contra ela disparados, enquanto dormia, a tentativa de eletrocutá-la, as agressões sofridas ao longo de sua relação com o agressor culminaram por deixá-la paraplégica aos 38 anos de idade. Apesar da condenação pela justiça local, após 15 anos o réu ainda permanecia em liberdade, valendo-se de sucessivos recursos processuais contra decisão condenatória do Tribunal do Júri. O caso motivou a apresentação de uma petição à Comissão Interamericana de Direitos Humanos (OEA), em 1998, pelas organizações CEJIL/Brasil (Centro para a Justiça e o Direito Internacional) e CLADEM/Brasil (Comitê Latinoamericano e do Caribe para a Defesa dos Direitos das Mulheres). Em 2001, em decisão inédita, a Comissão Interamericana condenou o Estado brasileiro por negligência e omissão em relação à violência doméstica
} 
Com 6 anos de vigência, a Lei Maria da Penha (LMP) ainda carece de plena efetividade. Se por um lado houve um aumento do número de registros policiais e processos judiciais em todo o país (Pasinato, 2010), houve também uma elevação na taxa de homicídios de mulheres. Em 2007, ano seguinte da vigência da LMP, a taxa caiu para 3,9 para cada 100 mil mulheres no Brasil. Em 2010, essa taxa se elevou para 4,6, mesmo índice do ano de 1996, cujo patamar alcança seu nível máximo (Waiselfisz, 2012).

De acordo com a atualização dos homicídios de mulheres no Mapa da Violência de 2012 (Waiselfisz, 2012), 14, 3\% dos homicídios de homens ocorrem na residência ou habitação. Para as mulheres, esse índice alcança 41\%. Quanto aos meios empregados, em $72,4 \%$ dos homicídios de homens são utilizadas arma de fogo. Ao passo que esse tipo de instrumento é utilizado em 49,2\% dos homicídios de mulheres. No homicídio de mulheres são utilizados meios que exigem maior contato físico, como objetos cortantes ou penetrantes (15,1\% em homens e $25,8 \%$ em mulheres), objetos contundentes $(5,3 \%$ em homens e $8,5 \%$ em mulheres), estrangulamento e sufocação (1,0\% em homens e 5,7\% em mulheres).

De acordo com o estudo de Tavares [et. all.] (2001: 12-13), apesar do investimento feito pelo Estado a fim de capacitar as equipes de atendimento em Delegacias Especializadas de Atendimento às Mulheres (DEAMs), estas equipes demonstram despreparo na condução dos atendimentos e realização dos procedimentos adequados, ou seja, os atendimentos são feitos com descaso e de forma rápida, as mulheres não são informadas acerca de seus direitos, suas dúvidas não são esclarecidas nem tampouco seus relatos e demandas são escutados.

As respostas oferecidas às mulheres nas DEAMs se mostram inadequadas e insuficientes, mas há outros elementos que tornam o guarda diante da LMP ainda mais operativo no enfrentamento da violência contra as mulheres.

No Rio Grande do Sul existe somente um juizado especializado em violência doméstica e familiar (JVDM), localizado no Foro Central de Porto Alegre. Conforme dados divulgados pelo o próprio juiz titular, no JVDM de Porto Alegre tramitava em agosto de 2011 mais de 20 mil processos, cujo perfil das usuárias é predominantemente de mulheres pobres e socialmente vulneráveis ${ }^{8}$.

suportada por Maria da Penha. (Comisión Interamericana de Derechos Humanos. Informe n. 54/01, caso 12.051, Maria da Penha Maia Fernandes v. Brasil, 16/04/2001).

${ }^{8}$ Dados divulgados pelo Dr. Roberto Arrriada Lorea em reunião no Forum de Enfrentamento à Violência Doméstica e Familiar contra as Mulheres, Porto Alegre, em 28/01/2011. 
Conforme o 'Relatório Anual' do Conselho Nacional de Justiça (2010), existem 43 JVDMs em todo o país. Nestes juizados especializados haviam em andamento 328.964 processos, tendo sido proferidas 108.882 decisões judiciais desde a entrada em vigência da LMP. Foram decretadas 11.659 prisões de agressores e, pela ordem, os estados com mais processos são Rio de Janeiro, Rio Grande do Sul e Minas Gerais.

A criação destes juizados é atribuição dos tribunais de justiça estaduais e do Distrito Federal. Na maioria dos estados, o que encontra são juizados especiais criminais (JECRIMs) e varas criminais adaptados para a aplicação da LMP.

De acordo com Pasinato (2011: 134), essa falta de compromisso dos tribunais de justiça tem provocado muitas limitações para que as mulheres em situação de violência doméstica e familiar tenham acesso aos seus direitos, especialmente nas comarcas localizadas no interior dos estados onde as varas atuam de forma ainda mais isolada, pela ausência de outros serviços especializados aos quais as mulheres possam recorrer.

Além da não ampliação - estrutural e funcional - dos JVDMs para todas as comarcas do país, há o problema crônico no sistema de justiça em relação a insuficiência de recursos humanos: há falta de servidores/as nos cartórios, de juízes/as e promotores/as titulares, de equipe multiprofissional, de oficiais de justiça. Em Porto Alegre, esses problemas comprometem o funcionamento adequado do JVDM: não há pauta para as audiências de avaliação das medidas protetivas de urgência à ofendida (arts. 23 e 24, da LMP); os processos ficam parados, por meses, aguardando a remessa dos inquéritos policiais ou diligências do Ministério Público. Não raras vezes as mulheres se frustram ainda mais quando é decretada a extinção dos processos por reconhecimento da prescrição da punibilidade do agressor, conforme art. 107, inciso IV, do Código Penal.

Em outras palavras, essas mulheres tiveram seu direito de acesso à justiça violado, uma vez que foram impedidas de acionar os procedimentos previstos na Lei Maria da Penha. O guarda em frente da Lei Maria da Penha tem se mostrado tão irredutível quanto na alegoria de Kafka.

É por isso que não basta uma nova lei, sem que as pessoas se reconheçam enquanto titulares de direitos. Uma das possibilidades de apropriação desse sentimento se dá através da educação para/em direitos humanos.

A experiência de democratização de noções legais básicas promovida pelas Promotoras Legais Populares fomenta o reconhecimento por parte das mulheres dos direitos de que são titulares. A consciência desta titularidade e dos meios de efetivá-la minimiza a 
descrença no Judiciário, bem como devolve à justiça o caráter de direito e não de serviço restrito apenas aos sujeitos consumidores; supre distâncias institucionais e cria ainda condições para a reivindicação de meios de supressão também das distâncias físicas (Massula, 2005: 167).

\section{Considerações finais}

Diante do contexto apresentado nesse ensaio podemos afirmar que as mulheres em situação de violência doméstica podem contar com uma Lei destinada a prevenir, erradicar e coibir a violência contra as mulheres. Entretanto, os guardas postos à frente da Lei Maria da Penha gozam da mesma função de obstaculização do acesso à justiça, tal qual representado na alegoria de Kafka, no diálogo entre os personagens Josef k. e o sacerdote.

No caso brasileiro, os guardas diante da lei estão postados nas delegacias de atendimento às mulheres, nos postos da defensoria pública, nas salas de audiências, nos postos de saúde e nos órgãos de assistência social quando não acolhem adequadamente, quando não escutam o que não é possível traduz em palavras, quando julgam em lugar de compreender.

Em termos concretos, a violência exercida no âmbito doméstico contra as mulheres tem sido poucas vezes impedida pelos agentes a quem a lei incumbe de fazê-lo, em um inequívoco processo de violência institucional e de negação do direito de acesso à justiça.

A questão posta em discussão é quais são as estratégias possíveis para deslocar esses guardas kafkanianos e reposiciona-los ao lado da lei e das mulheres em situação de violência doméstica. A experiência de educação popular jurídica com as Promotoras Legais Populares, representa uma possibilidade concreta de promoção de uma mudança cultural nos guardas postados diante da lei.

\section{Referencias bibliográficas}

BARACHO, J. A. de O. Teoria Geral da Cidadania: a plenitude da cidadania e as garantias constitucionais e processuais. São Paulo: Saraiva, 1995.

CAPPELlETTI, M.; GARTH, B. Acesso à Justiça. Porto Alegre: Fabris Editor, 1988.

CAULFIELD. S. Em defesa da honra: moralidade, modernidade e nação no Rio de Janeiro (19181940). Campinas: Ed. UNICAMP, 2000. 
CNJ. Relatório Anual do Conselho Nacional de Justiça, 2010.

CORRÊA, M. Morte em família. Representação jurídica de papéis sociais. São Paulo: Ed.Graal, 1983.

DELGADO, J. A. A supremacia dos princípios nas garantias processuais do cidadão. Revista de Informação Legislativa, ano 31, n. 123, jul./set. 1994.

DIEESE. Anuário das Mulheres Brasileiras. São Paulo: DIEESE, 2011. Disponível em http://www.dieese.org.br/anu/anuarioMulheresBrasileiras2011.pdf. Acesso em 28/7/2012.

FEIX, V. Por uma política pública nacional de acesso à justiça. Estudos Avançados, São Paulo, n. 18, v. 51, 2004, p. 219-225.

FEIX. V. Sobre gênero e justiça: o Projeto Promotoras Legais Populares. Disponível em http://www.pagu.unicamp.br/sites/www.pagu.unicamp.br/files/colenc.01.a10.pdf. Acesso em $17 / 08 / 2012$.

GRINOVER, A. P. As garantias constitucionais do direito de ação. São Paulo: Revista dos Tribunais, 1973.

IBGE. Pesquisa Mensal de Emprego: mulher no mercado de trabalho - perguntas e respostas. Brasília: $\quad$ IBGE, 2012. Disponível em http://www.ibge.gov.br/home/estatistica/indicadores/trabalhoerendimento/pme_nova/Mulher_ Mercado_Trabalho_Perg_Resp_2012.pdf. Acesso em 28/7/2012.

IBGE. Síntese de Indicadores Sociais: uma análise das condições de vida da população brasileira. Brasília: $\quad$ IBGE, 2010. Disponível em http://www.ibge.gov.br/home/estatistica/populacao/condicaodevida/indicadoresminimos/sinte seindicsociais2010/SIS 2010.pdf. Acesso em 28/7/2012.

IPEA. Seminário discutiu as condições das trabalhadoras domésticas. 29/6/2011. Disponível em

http://www.ipea.gov.br/portal/index.php?option=com_content\&view=article\&id=9262\&Itemi $\underline{\mathrm{d}=1}$. Acesso em 28/7/2012.

JAPIASSÚ, H.; MARCONDES, D. Dicionário Básico de Filosofia. 3. ed. rev. e ampl. Rio de Janeiro: Jorge Zahar Ed., 1996.

MASSULA, L. A violência e o acesso das mulheres à justiça: O caminho das pedras ou as pedras do (no) caminho. 2005.

NERY JUNIOR, N. Princípios do Processo Civil na Constituição Federal. 6. ed. rev., ampl. e atual. São Paulo: Revista dos Tribunais, 2000.

ONU Mujeres. El Progreso de las Mujeres em el mundo: en busca de justicia (2011-2012). Disponível em: http://progress.unwomen.org. Acesso em 17/08/2012. 
PASINATO, W. Delegacias de Defesa da Mulher e Juizados Especiais Criminais: mulheres, violência e acesso à justiça. XXVIII Encontro da Associação Nacional de Pós-Graduação em Ciências Sociais - ANPOCS. Out./2004.

PASINATO, W. Relatório Final: Condições para aplicação da Lei 11.340/2006 (Lei Maria da Penha) nas Delegacias Especializadas de Atendimento à Mulher (DEAMS) e nos Juizados de Violência Doméstica e Familiar nas capitais e no Distrito Federal. Ago./2010. Disponível em: http://www.observe.ufba.br/ ARQ/Relatorio\%20apresent\%20e\%20DEAMs.pdf. Acesso em $17 / 08 / 2012$.

PASINATO, W. Avanços e obstáculos na implementação da Lei 11.340/2006. In: CAMPOS, C. H de. Lei Maria da Penha - Comentada em uma perspectiva jurídico-feminista. Rio de Janeiro: Lumen Juris, 2011, p. 119-142.

PIMENTEL, S.; SCHRITZMEYER, A. L.; PANDJIARJIAN, V. Estupro: crime ou "cortesia"? Abordagem sociojurídica de gênero. Porto Alegre: Fabris Editor, 1998.

PORTANOVA, R. Princípios do processo civil. 3. ed. Porto Alegre: Livraria do Advogado, 1999.

SARTI, C. A.; BARBOSA, R. M.; SUAREZ, M. M..Violência e Gênero: vítimas demarcadas. PHYSIS: Revista de Saúde Coletiva, Rio de Janeiro, n. 16, vol. 2, 2006, p. 167-183.

SCOTT, J. W. Gênero: uma categoria útil de análise histórica. Educação e Realidade, Porto Alegre, 1990, p. 10-34.

SILVEIRA, I. A.; PASINI, E.; CRUZ, R. A. Nominando o Inominável: violência contra a mulher e o Poder Judiciário. Porto Alegre: THEMIS, 2008.

SIMIONI, F.; CRUZ, R. Da violência doméstica e familiar - artigo $5^{\circ}$. In: CAMPOS, C. H. de. Lei Maria da Penha - Comentada em uma perspectiva jurídico-feminista. Rio de Janeiro: Lumen Juris, 2011, p. 185-195.

TAVARES, M.; GOMES, M. SARDENBERG, C. O acesso à justiça no Brasil das mulheres em situação de violência. XV Congresso Brasileiro de Sociologia. Jul./2011. Disponível em; www.sbsociologia.com.br/. Acesso em 17/08/2012.

WAISELFISZ, J. J. Mapa da Violência 2012. Atualização: Homicídios de Mulheres no Brasil. Ago./2012. Disponível em: http://www.mapadaviolencia.org.br/pdf2012/MapaViolencia2012_atual_mulheres.pdf. Acesso em 17/08/2012. 